\title{
Receptor protein tyrosine phosphatase beta/zeta is a functional binding partner for vascular endothelial growth factor
}

Marina Koutsioumpa ${ }^{1,6}$, Evangelia Poimenidi ${ }^{1}$, Evangelia Pantazaka ${ }^{1}$, Christina Theodoropoulou$^{1}$, Angeliki Skoura², Vasileios Megalooikonomou' ${ }^{2}$, Nelly Kieffer ${ }^{3}$, Jose Courty ${ }^{4}$, Shuji Mizumoto ${ }^{5,7}$, Kazuyuki Sugahara ${ }^{5}$ and Evangelia Papadimitriou ${ }^{1 *}$

\begin{abstract}
Background: Receptor protein tyrosine phosphatase beta/zeta (RPTP $\beta / \zeta$ ) is a chondroitin sulphate (CS) transmembrane protein tyrosine phosphatase and is a receptor for pleiotrophin (PTN). RPTP $\beta / \zeta$ interacts with $a_{v} \beta_{3}$ on the cell surface and upon binding of PTN leads to c-Src dephosphorylation at Tyr530, $\beta_{3}$ Tyr773 phosphorylation, cell surface nucleolin (NCL) localization and stimulation of cell migration. c-Src-mediated $\beta_{3}$ Tyr773 phosphorylation is also observed after vascular endothelial growth factor $165\left(\right.$ VEGF $\left._{165}\right)$ stimulation of endothelial cells and is essential for VEGF receptor type 2 (VEGFR2) - $a_{v} \beta_{3}$ integrin association and subsequent signaling. In the present work, we studied whether RPTP $\beta / \zeta$ mediates angiogenic actions of VEGF.

Methods: Human umbilical vein endothelial, human glioma U87MG and stably transfected Chinese hamster ovary cells expressing different $\beta_{3}$ subunits were used. Protein-protein interactions were studied by a combination of immunoprecipitation/Western blot, immunofluorescence and proximity ligation assays, properly quantified as needed. RPTP $\beta / \zeta$ expression was down-regulated using small interference RNA technology. Migration assays were performed in 24-well microchemotaxis chambers, using uncoated polycarbonate membranes with $8 \mu \mathrm{m}$ pores.

Results: RPTP $\beta / \zeta$ mediates VEGF 165 -induced c-Src-dependent $\beta_{3}$ Tyr773 phosphorylation, which is required for VEGFR2-av $\beta_{3}$ interaction and the downstream activation of phosphatidylinositol 3-kinase (PI3K) and cell surface NCL localization. RPTP $\beta / \zeta$ directly interacts with $\mathrm{VEGF}_{165}$, and this interaction is not affected by bevacizumab, while it is interrupted by both CS-E and PTN. Down-regulation of RPTP $\beta / \zeta$ by siRNA or administration of exogenous CS-E abolishes VEGF 165 -induced endothelial cell migration, while PTN inhibits the migratory effect of VEGF 165 to the levels of its own effect.

Conclusions: These data identify RPTP $\beta / \zeta$ as a cell membrane binding partner for VEGF that regulates angiogenic functions of endothelial cells and suggest that it warrants further validation as a potential target for development of additive or alternative anti-VEGF therapies.
\end{abstract}

Keywords: Chondroitin sulphate, Endothelial cells, Migration, Pleiotrophin, Tyrosine phosphatases, Vascular endothelial growth factor

\footnotetext{
* Correspondence: epapad@upatras.gr

'Laboratory of Molecular Pharmacology, Department of Pharmacy, University

of Patras, GR 26504 Patras, Greece

Full list of author information is available at the end of the article
} 


\section{Background}

Vascular endothelial growth factor A (VEGF) is a growth factor that activates several functions of endothelial cells, thus triggering angiogenesis and vascular permeability. It exists as different isoforms of 121, 145, 165, 189 and 206 amino acids, among which VEGF 165 is dominant in terms of amount and biological activity. $\mathrm{VEGF}_{165}$ is overexpressed in a variety of human tumors, and its overexpression is correlated with progression, invasion, and metastasis of tumors. VEGF $_{165}$ cell signaling leading to increased endothelial cell migration and tubular formation is mediated via vascular endothelial growth factor receptor 2 (VEGFR2), which interacts with co-receptors, such as $\alpha_{v} \beta_{3}$ integrin [1]. It has been shown that c-Srcmediated phosphorylation of $\beta_{3}$ cytoplasmic tail tyrosine residues occurs in response to VEGF 165 and is essential for VEGFR2- $\beta_{3}$ integrin association and subsequent signaling [2,3]. Up to date, it remains unclear how c-Src is activated by $\mathrm{VEGF}_{165}$. The first step in c-Src activation requires dephosphorylation of its carboxy-terminus Tyr530 [4], suggesting that a tyrosine phosphatase may be involved.

Receptor protein tyrosine phosphatase beta/zeta (RPTP $\beta / \zeta)$ is a member of the family of receptor-type transmembrane protein tyrosine phosphatases that interacts with several cell adhesion molecules, such as neutral cell adhesion molecule, neuron-glia cell adhesion molecule, tenascin and contactin. It also acts as a receptor for the soluble, heparin-binding growth factors midkine and pleiotrophin (PTN) [5]. RPTP $\beta / \zeta$ and PTN are expressed in endothelial cells [6] and over-expressed in several types of cancer [5,7]. PTN binding to RPTP $\beta / \zeta$ on endothelial cells leads to Tyr530 dephosphorylation and activation of c-Src, $\beta_{3}$ Tyr773 phosphorylation, and PTN-induced endothelial cell migration and tube formation on matrigel $[5,8]$. Besides PTN, RPTP $\beta / \zeta$ has been shown to be the putative receptor for the vacuolating cytotoxin VacA produced by Helicobacter pylori [9], as well as a functional receptor for interleukin-34 [10], suggesting that it acts as a functional binding partner for several soluble molecules.

We have recently shown that RPTP $\beta / \zeta$-induced, c-Srcmediated $\beta_{3}$ Tyr773 phosphorylation is also required for PTN-induced cell surface nucleolin (NCL) localization [11]. NCL is over-expressed on the plasma membrane of cancer and activated endothelial cells and has been shown to play critical roles in the modulation of tumorigenesis and angiogenesis through its interaction with a variety of ligands, among which tumor homing peptide F3, endostatin, P-selectin and PTN [12]. VEGF 165 induces NCL localization on the surface of endothelial cells and this effect is considered important for its angiogenic actions $[13,14]$; however, the receptors and pathways involved have not been elucidated.
In the present work, we explored the possibility that $\mathrm{RPTP} \beta / \zeta$ is involved in the stimulatory effect of $\mathrm{VEGF}_{165}$ on endothelial cell signaling leading to cell migration. Our data show that $\mathrm{VEGF}_{165}$ directly interacts with $\mathrm{RPTP} \beta / \zeta$ to induce c-Src-mediated $\beta_{3}$ Tyr773 phosphorylation. The latter is required for both cell surface NCL localization and increased interaction of $\alpha_{v} \beta_{3}$ with VEGFR2, leading to $\mathrm{VEGF}_{165}$-induced endothelial cell migration.

\section{Results and discussion}

Phosphorylation of $\beta_{3}$ Tyr773 is required for VEGF $_{165^{-}}$ induced cell migration and cell surface NCL localization It has been shown that phosphorylation of $\beta_{3}$ cytoplasmic Tyr 773 and 785 in response to $V_{E G F} 165$ plays a role in endothelial cell migration [2]. In order to determine which of the two Tyr is responsible for $\mathrm{VEGF}_{165}$-induced cell migration, we used $\mathrm{CHO}$ cells that express VEGFR2 (Figure $1 \mathrm{~A}$ ), RPTP $\beta / \zeta$ and $\alpha_{v}[8,11]$, but do not express $\beta_{3}$ and are mock-transfected or stably transfected to over-express wild-type $\beta_{3}$ or $\beta_{3}$ in which Tyr773 and/or Tyr785 are mutated to Phe [11]. VEGF 165 induced migration of $\mathrm{CHO}$ cells over-expressing wild type $\beta_{3}$ or $\beta_{3}$ Y785F, but had no effect on $\mathrm{CHO}$ cells over-expressing $\beta_{3} Y 773 \mathrm{~F}$ or $\beta_{3} \mathrm{Y} 773 \mathrm{~F} / \mathrm{Y} 785 \mathrm{~F}$ (Figure $1 \mathrm{~B}$ ), suggesting that $\beta_{3}$ Tyr773 is important for VEGF 165 -induced cell migration. In the same line and similarly to what we have recently shown for PTN [11], VEGF 165 -induced cell surface NCL localization was only observed in $\mathrm{CHO}$ cells overexpressing wild type- $\beta_{3}$ or $\beta_{3}$ Y785F, while in cells overexpressing $\beta_{3} \mathrm{Y} 773 \mathrm{~F}$, NCL remained restricted in the cell nucleus, suggesting that $\beta_{3}$ Tyr773 but not Tyr785 phosphorylation is important for $\mathrm{VEGF}_{165}$-induced cell surface NCL localization (Figure 1C). Since RPTP $\beta / \zeta$ is involved in PTN-induced $\beta_{3}$ Tyr773 phosphorylation and cell surface NCL localization $[8,11]$, these data lead to the hypothesis that $\mathrm{RPTP} \beta / \zeta$ may also be involved in $\mathrm{VEGF}_{165}$-induced signaling that leads to endothelial cell migration.

\section{$\mathrm{RPTP} \beta / \zeta$ plays a role in $\mathrm{VEGF}_{165}$-induced endothelial cell signaling that leads to cell surface NCL localization}

Since RPTP $\beta / \zeta$ is responsible for PTN-induced $\beta_{3}$ Tyr773 phosphorylation through dephosphorylation and activation of c-Src in human umbilical vein endothelial cells (HUVEC) [8], we examined whether RPTP $\beta / \zeta$ also affects VEGF $_{165}$-induced $\mathrm{c}$-Src activation and $\beta_{3}$ Tyr773 phosphorylation. Down-regulation of RPTP $\beta / \zeta$ expression by two different siRNAs abolished $\mathrm{VEGF}_{165}$-induced dephosphorylation of c-Src at Tyr530 (Figure 2A), suggesting that $\mathrm{RPTP} \beta / \zeta$ may be the missing link for c-Src activation upon stimulation of endothelial cells with $\mathrm{VEGF}_{165}$. Indeed, the increase in dephosphorylated c-Src Tyr530 was mirrored by higher phosphorylation of c-Src at Tyr419 (Figure 2A), 

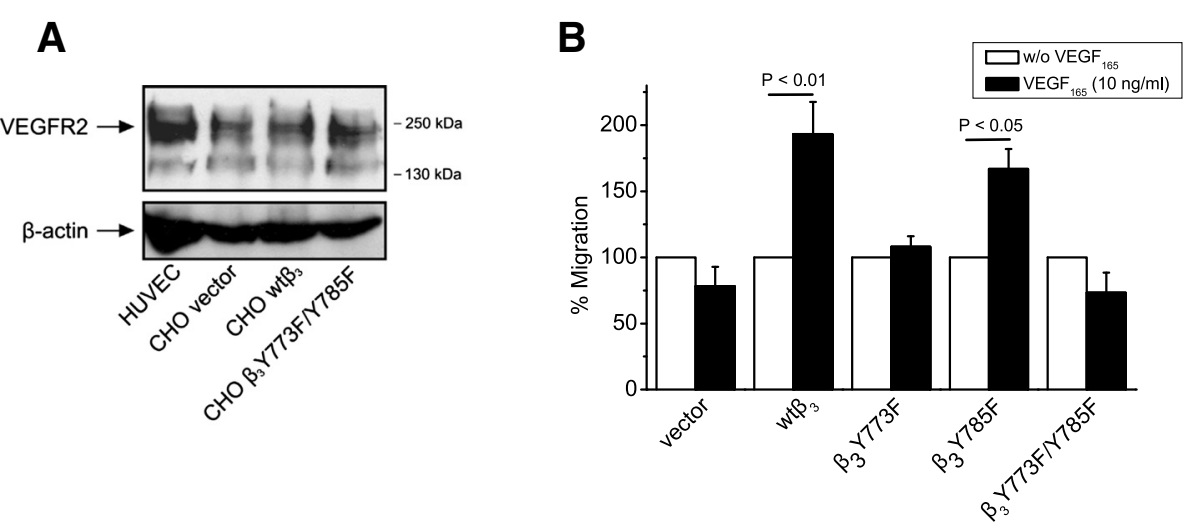

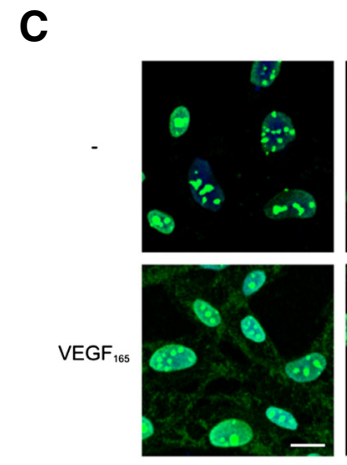

$w t \beta_{3}$

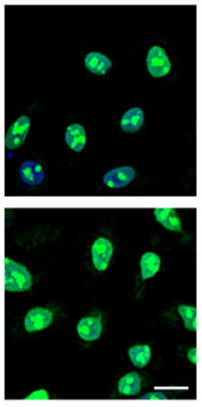

$\beta_{3} Y 773 F$

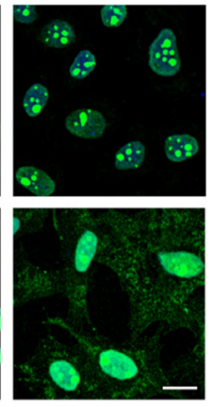

$\beta_{3} Y 785 F$

Figure 1 Phosphorylation of $\beta_{3}$ Tyr773 is required for $\mathrm{VEGF}_{165}$-induced cell migration and cell surface NCL localization. (A) Protein extracts of $\mathrm{CHO}$ cells were analysed for expression of VEGFR2. HUVEC were used as a positive control and $\beta$-actin as a loading control. (B) Effect of VEGF $_{165}(10 \mathrm{ng} / \mathrm{ml})$ on $\mathrm{CHO}$ cell migration. Data are from five independent experiments and are expressed as mean \pm s.e.m. percentage change in number of migrating cells compared with the corresponding non stimulated cells (set as default 100). (C) Immunofluorescence images stained for NCL (green) and nucleus (blue) in serum starved CHO cells treated with VEGF $165(10 \mathrm{ng} / \mathrm{ml})$ for $5 \mathrm{~h}$ at $37^{\circ} \mathrm{C}$. Vector, cells transfected with the plasmid vector; wt $\beta_{3}$, cells over-expressing wild-type $\beta_{3} ; \beta_{3} Y 773 \mathrm{~F}$, cells over-expressing $\beta_{3} Y 773 \mathrm{~F} ; \beta_{3} Y 785 \mathrm{~F}$, cells over-expressing $\beta_{3} Y 785 F ; \beta_{3} Y 773 F / Y 785 F$, cells over-expressing double mutant $\beta_{3} Y 773 F / Y 785 F$.

verifying activation of c-Src. Interestingly, inhibition of VEGFR2 tyrosine kinase activity by the selective inhibitor SU1498 or inhibition of VEGF-VEGFR2 interaction by bevacizumab, did not affect $\mathrm{VEGF}_{165}$-induced c-Src Tyr530 dephosphorylation or c-Src Tyr419 phosphorylation (Additional file 1), suggesting that $\mathrm{c}$-Src activation may be independent of VEGFR2 in these assays. RPTP $\beta / \zeta$ directly interacts with c-Src [6], an observation that is in line with a role for RPTP $\beta / \zeta$ in c-Src activation. Downregulation of RPTP $\beta / \zeta$ expression also abolished $\mathrm{VEGF}_{165^{-}}$ induced $\beta_{3}$ Tyr773 phosphorylation (Figure $2 \mathrm{~B}$ ), suggesting that $\mathrm{RPTP} \beta / \zeta$ may be involved in $\mathrm{VEGF}_{165}$-induced signaling related to cell surface NCL localization, as has been previously described for PTN [11]. Indeed, downregulation of $\mathrm{RPTP} \beta / \zeta$ expression abolished $\mathrm{VEGF}_{165}$-induced cell surface NCL localization (Figure 2C). Although it has been known for several years that VEGF $_{165}$ induces cell surface NCL localization [13], which is required for VEGF $_{165}$-induced cell migration [14], the receptor/pathway involved was unknown up to date. The observation that $\mathrm{VEGF}_{165}$-induced cell surface NCL localization depends on $\mathrm{RPTP} \beta / \zeta$ suggests a role for $\mathrm{RPTP} \beta / \zeta$ in the angiogenic effects of $\mathrm{VEGF}_{165}$.

To further investigate the involvement of RPTP $\beta / \zeta$ in VEGF actions, we studied the role of several signaling molecules known to be activated by both VEGF 165 and RPTP $\beta / \zeta$ on cell surface NCL localization. Inhibition of c-Src and phosphatidylinositol 3-kinase (PI3K) abolished $\mathrm{VEGF}_{165}$-induced cell surface NCL localization, while inhibition of ERK1/2 had no effect (Figure 2D). In order to investigate whether PI3K lays up- or downstream of $\alpha_{v} \beta_{3}$, the effect of PI3K inhibition on VEGF ${ }_{165}$-induced $\beta_{3}$ Tyr773 phosphorylation was studied. The c-Src inhibitor PP1 was used as a positive control, since c-Src is known to lay upstream of $\beta_{3}$ Tyr773 phosphorylation $[2,8,11]$. The p38 inhibitor (SB203580 $10 \mu \mathrm{M}$, BioSource Europe, Nivelles, Belgium) was used as a negative control, since it has been previously shown not to affect RPTP $\beta / \zeta$ mediated $\beta_{3}$ Tyr773 phosphorylation and PI3K activation [11]. PI3K inhibition did not affect $\mathrm{VEGF}_{165}$-induced $\beta_{3}$ 


\section{A}

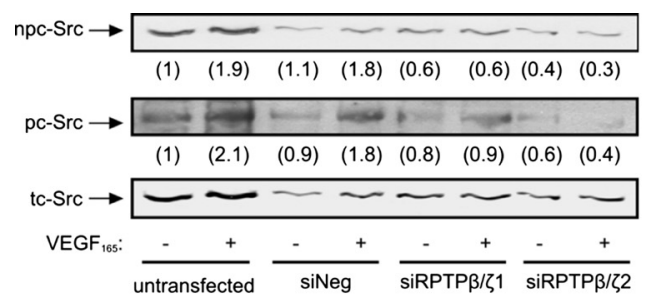

C
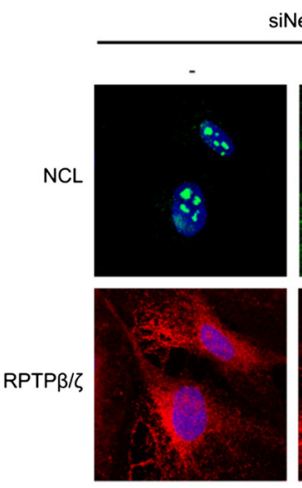

D

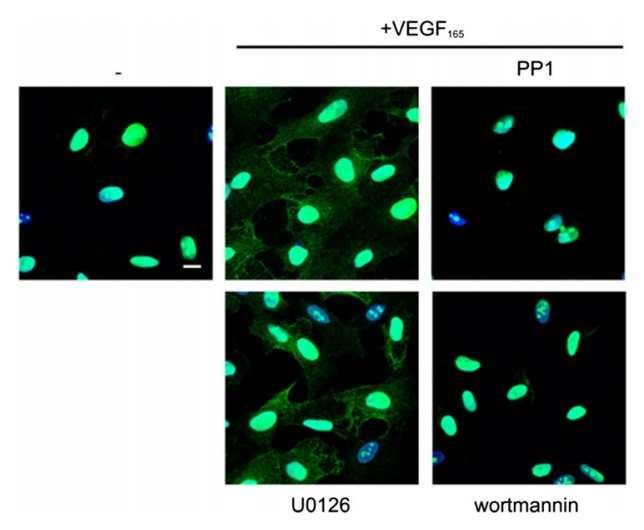

F

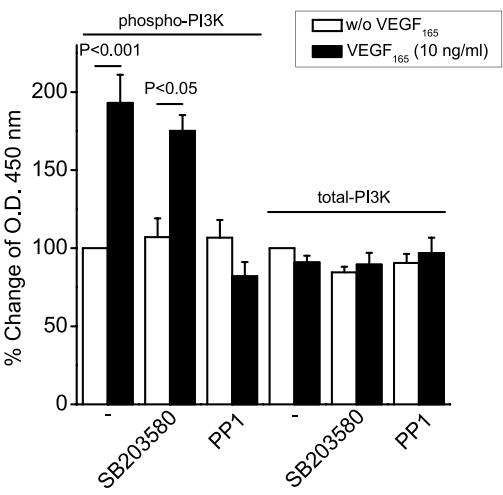

\section{B}

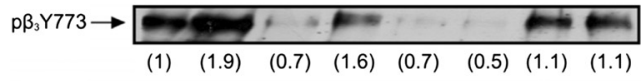

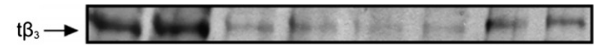

VEGF $_{165:} \frac{-+}{\text { untransfected }} \frac{-+}{\text { siNeg }} \frac{-+}{\text { siRPTP } \beta / \zeta 1} \frac{-}{\text { siRPTP } \beta / \zeta 2}$
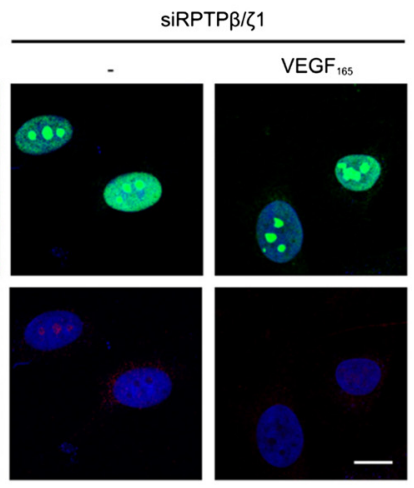

E
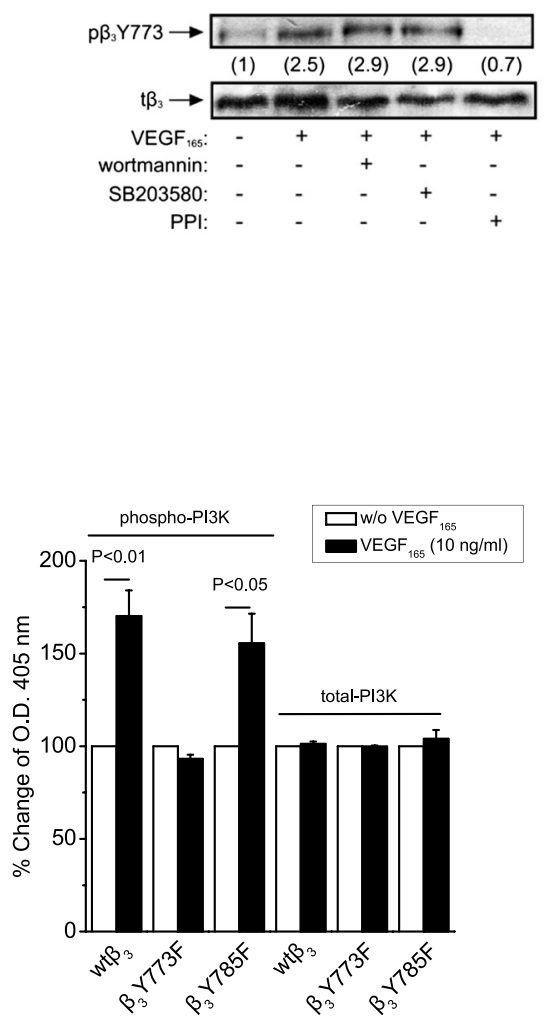

Figure $\mathbf{2}$ (See legend on next page.) 
(See figure on previous page.)

Figure 2 RPTP $\beta / \zeta$ is required for VEGF $_{\mathbf{1 6 5}}$-induced cell surface $\mathbf{N C L}$ localization. Serum starved HUVEC were treated with VEGF 165 (10 ng/ml) for $10 \mathrm{~min}$. Cell lysates were analyzed by Western blot for non Tyr530 phosphorylated (npc-Src), Tyr419 phosphorylated (pc-Src) and total (tc-Src) $c-\operatorname{Src}(\mathbf{A})$, as well as for phospho- $\beta_{3} Y 773\left(p \beta_{3} Y 773\right)$ and total $\beta_{3}\left(t \beta_{3}\right)$ integrin (B). Numbers in brackets denote the average-fold change of the ratio npc-Src:tc-Src, pc-Src:tc-Src or $\mathrm{p} \beta_{3} Y 773: \mathrm{t} \beta_{3}$ respectively, compared with the corresponding non stimulated, untransfected cells (set as default 1). (C) Representative immunofluorescence images stained for NCL (green), RPTP $/ \zeta$ (red) and nucleus (blue) from serum starved HUVEC treated with VEGF $_{165}(10 \mathrm{ng} / \mathrm{ml})$ for $5 \mathrm{~h}$ at $37^{\circ} \mathrm{C}$. (D) Representative immunofluorescence images stained for $\mathrm{NCL}$ (green) and nucleus (blue) from serum starved VEGF $_{165}$-stimulated HUVEC in the presence or absence of inhibitors for c-Src (PP1 $10 \mu \mathrm{MM}$ ), PI3K (wortmannin $\left.100 \mathrm{nM}\right)$ and ERK1/2 (U0126 $20 \mathrm{nM}$ ). Scale bars in $\mathbf{C}$ and $\mathbf{D}$ correspond to $10 \mu \mathrm{m}$. (E) Lysates from serum starved VEGF $165^{-}$stimulated HUVEC in the presence or absence of PP1 and wortmannin, were analyzed by Western blot for $\mathrm{p} \beta_{3} Y 773$ and $t \beta_{3}$ integrin. Numbers in brackets denote the average-fold change of the ratio $p \beta_{3} Y 773: t \beta_{3}$ compared with untreated cells (set as default 1). (F and G) Phosphorylation of PI3K in HUVEC and CHO cells respectively. Data are expressed as mean \pm s.e.m percentage change in PI3K compared with the untreated cells (set as default 100). In all cases, data come from three independent experiments. siNeg, HUVEC transfected with a negative control siRNA; siRPTP $\beta /$ /, HUVEC transfected with siRPTP $\beta /$ / 1 ; siRPTP $\beta /$ /2, HUVEC transfected with si RPTP $\beta /$ /Z2; vector, $\mathrm{CHO}$ cells transfected with the plasmid vector; wt $\beta_{3}, \mathrm{CHO}$ cells over-expressing wild-type $\beta_{3} ; \beta_{3} \mathrm{Y} 773 \mathrm{~F}$, CHO cells over-expressing $\beta_{3} Y 773 \mathrm{~F}$; $\beta_{3}$ Y785F, CHO cells over-expressing $\beta_{3}$ Y785F.

Tyr773 phosphorylation (Figure 2E), suggesting that it lays downstream of $\alpha_{v} \beta_{3}$. By using an ELISA for activated PI3K in HUVEC, it was found that inhibition of c-Src abolished $\mathrm{VEGF}_{165}$-induced PI3K activation (Figure 2F). Using the same assay in $\mathrm{CHO}$ cells over-expressing wild-type $\beta_{3}$, $\beta_{3}$ Y773F or $\beta_{3} Y 785 F$, it was found that $V_{E G F} 165$ significantly induced PI3K activation in $\mathrm{CHO}$ cells overexpressing wild-type $\beta_{3}$ or $\beta_{3}$ Y785F, while it had no effect in cells over-expressing $\beta_{3}$ Y773F (Figure 2G), suggesting that PI3K lays downstream of $\alpha_{v} \beta_{3}$ and requires $\beta_{3}$ Tyr773 phosphorylation. This pathway resembles the one we have recently shown for PTN-induced cell surface NCL localization [11], further supporting the notion that $\mathrm{RPTP} \beta / \zeta$ mediates this effect of $\mathrm{VEGF}_{165}$. Similarly to what has been previously discussed for PTN, it remains unclear how PI3K affects cell surface NCL localization. Co-immunoprecipitation of NCL with PI3K $[15,16]$ favors a direct regulation of NCL by PI3K and one possibility is by regulating the trafficking of exocytotic vesicles. NCL has been detected in cytoplasmic vesicles fused with the plasma membrane [17], while inhibition of PI3K interferes with the trafficking of such exocytotic vesicles, affecting the number of several receptors on the plasma membrane, such as the transferrin receptor [18], the glucose transporter GLUT4 [19] or $\beta$ integrin [20]. Alternatively, PI3K may indirectly regulate cell surface NCL localization, by regulating recruitment of proteins containing pleckstrin homology domains onto the cell membrane [21]. NCL does not possess such sequences but may act as a ligand for proteins containing pleckstrin homology domains through its acidic motifs [22].

\section{$\mathrm{RPTP} \beta / \zeta$ plays a role in $\mathrm{VEGF}_{165}$-induced interaction of VEGFR2 with $a_{v} \beta_{3}$}

Based on the literature that $\mathrm{c}$-Src-mediated phosphorylation of $\beta_{3}$ essentially regulates $\mathrm{VEGF}_{165}$-induced interaction of $\alpha_{v} \beta_{3}$ with VEGFR2 in endothelial cells [2] and our observation that $\mathrm{RPTP} \beta / \zeta$ is required for $\mathrm{VEGF}_{165^{-}}$ induced c-Src activation and $\beta_{3}$ Tyr773 phosphorylation (Figure 2), we tested the hypothesis that $\mathrm{RPTP} \beta / \zeta$ may have a role in the interaction of $\alpha_{v} \beta_{3}$ with VEGFR2. Down-regulation of $\mathrm{RPTP} \beta / \zeta$ expression by siRNA abolished the increased interaction of $\alpha_{v} \beta_{3}$ with VEGFR2 induced by $\mathrm{VEGF}_{165}$, as evidenced by both immunoprecipitation/Western blot (Figure 3A) and proximity ligation assays (PLA) (Figure 3B). These data also show involvement of RPTP $\beta / \zeta$ in VEGF-induced endothelial cell migration.

\section{$\mathrm{RPTP} \beta / \zeta$ plays a role in $\mathrm{VEGF}_{165}$-induced endothelial cell migration}

Since $\mathrm{RPTP} \beta / \zeta$ affects $\mathrm{VEGF}_{165}$-induced signaling related to cell migration, we tested whether it also affects $\mathrm{VEGF}_{165^{-}}$ induced endothelial cell migration. Down-regulation of $\mathrm{RPTP} \beta / \zeta$ expression by siRNA abolished $\mathrm{VEGF}_{165^{-}}$ induced HUVEC migration (Figure 4), highlighting a role for $\mathrm{RPTP} \beta / \zeta$ in the angiogenic effects of $\mathrm{VEGF}_{165}$.

\section{VEGF directly interacts with RPTP $\beta / \zeta$}

It has been previously shown that $\mathrm{RPTP} \beta / \zeta$ interacts with both $\alpha_{v} \beta_{3}$ and NCL in HUVEC $[8,11]$, both of which are involved in $\mathrm{VEGF}_{165}$-induced endothelial cell migration $[2,3,13,14]$. Since VEGFR2 is also required for VEGF $_{165}$-induced endothelial cell migration [1], we tested whether $\mathrm{RPTP} \beta / \zeta$ interacts with VEGFR2. By performing immunoprecipitation/Western blot and PLA assays, we found that VEGFR2 does not associate with $\mathrm{RPTP} \beta / \zeta$ (Figure $5 \mathrm{~A}$ ). We then tested the possibility that VEGF directly associates with $\mathrm{RPTP} \beta / \zeta$ by performing PLA assays in HUVEC, which express endogenous levels of VEGF (Additional file 2). As shown in Figure 5B, endogenous VEGF formed complexes with $\mathrm{RPTP} \beta / \zeta$, suggesting a direct interaction between the two molecules. Interestingly, addition of exogenous VEGF $_{165}$ to HUVEC, which led to increased VEGF immunostaining (Additional file 2), increased VEGF-RPTP $\beta / \zeta$ PLA signals (Figure $5 \mathrm{~B}$ ), verifying the specificity of the signal. In these 
A

$$
\mathrm{IP}: \beta_{3}
$$

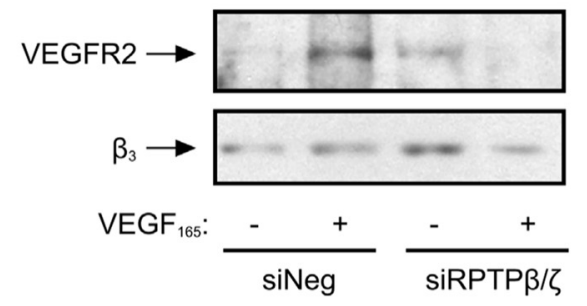

B

VEGFR2 - $\alpha_{v} \beta_{3}$

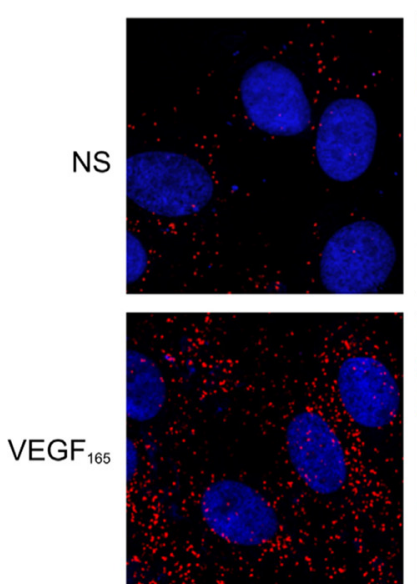

control
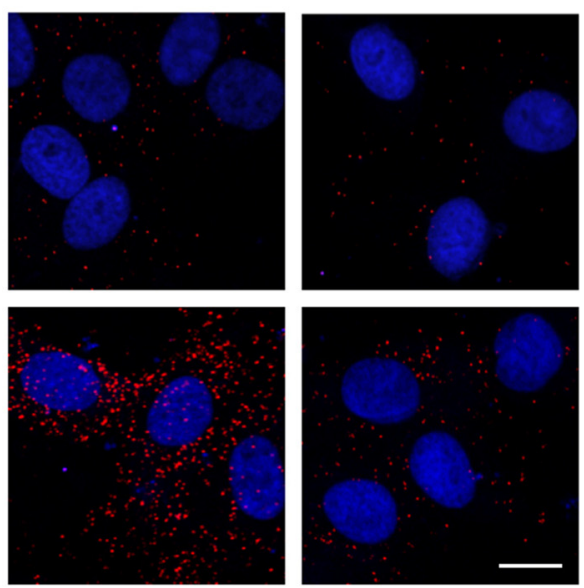

siNeg

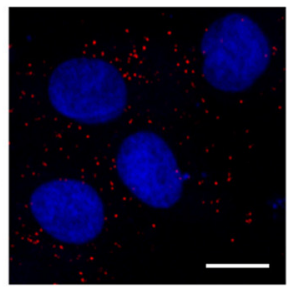

siRPTP $\beta / \zeta$

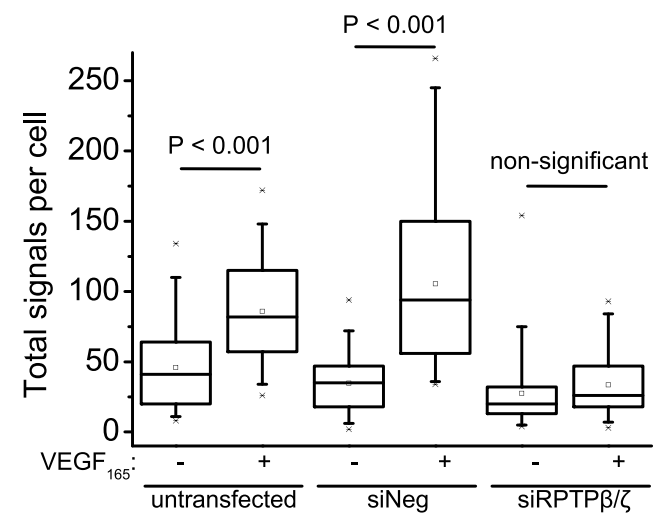

Figure 3 RPTP $\beta / \zeta$ regulates VEGF 165 -induced VEGFR2- $\boldsymbol{a}_{v} \beta_{3}$ interaction. Down-regulation of RPTP $\beta / \zeta$ expression by siRNA was followed by treatment of serum-starved HUVEC with VEGF $165(10 \mathrm{ng} / \mathrm{ml})$ for $10 \mathrm{~min}$. (A) Cells lysates were immunoprecipitated for $\beta_{3}$ and analyzed by Western blot for the presence of VEGFR2 and $\beta_{3}$. (B) Formation of $\beta_{3}$-VEGFR2 complexes as evidenced by in situ PLA. The box plots indicate the median, mean and range of the detected signals ( $n=8$ image fields with $\sim 4$ cells per image per sample type, each sample run in duplicate). Scale bar corresponds to $10 \mu \mathrm{m}$. siNeg, HUVEC transfected with a negative control siRNA; siRPTP $\beta / \zeta$, HUVEC transfected with siRPTP $\beta / \zeta \# 1$.

assays, the interaction of VEGF with VEGFR2 was used as positive control. Interaction of VEGF with $\mathrm{RPTP} \beta / \zeta$ was also observed in human glioblastoma U87MG cells, by using a combination of immunoprecipitation/Western blot, double immunofluorescence and PLA assays. These cells express higher levels of endogenous VEGF compared with HUVEC and the PLA signals showing interaction with $\mathrm{RPTP} \beta / \zeta$ were also higher than those 

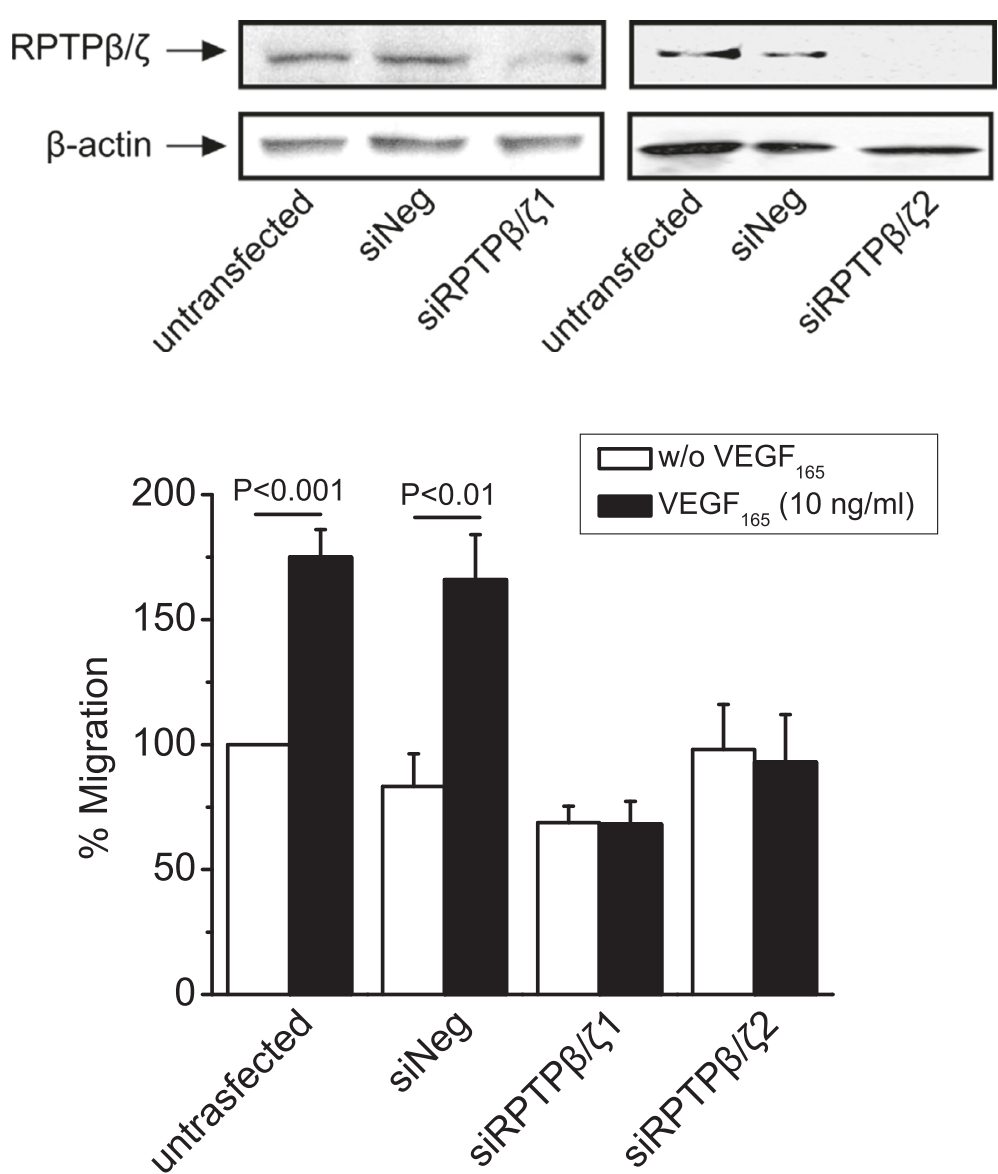

Figure $4 \mathrm{RPTP} \beta / \zeta$ is required for $\mathrm{VEGF}_{165}$-induced endothelial cell migration. Effect of $\mathrm{VEGF}_{165}$ on HUVEC migration after down-regulation of RPTP $\beta / \zeta$ expression by two different siRNAs. Data are from five independent experiments and are expressed as mean \pm s.e.m. percentage change in number of migrating cells compared with the non stimulated untransfected cells (set as default 100). Untrasfected, untransfected HUVEC; siNeg, HUVEC transfected with a negative control siRNA; siRPTP $\beta / \zeta 1$, HUVEC transfected with siRPTP $\beta / / \# 1$; siRPTP $\beta / \zeta 2$, HUVEC transfected with si RPTP $\beta /$ /Z2. The Western blot on top shows effective down-regulation of RPTP $\beta / \zeta$ by both siRNA sequences used.

observed in HUVEC (Additional file 2). Interestingly, VEGF was not found to interact with $\alpha_{v} \beta_{3}$ (Additional file 3).

Bevacizumab used at a concentration that inhibits VEGF-induced cell migration and binding to both VEGFR1 and VEGFR2 [23], did not affect interaction of VEGF with $R P T P \beta / \zeta$ (Figure $5 C$ ), suggesting that this interaction involves a different region on the VEGF molecule than the VEGFR binding site. Supporting this notion, bevacizumab did not inhibit $\mathrm{VEGF}_{165}$-induced cell surface NCL localization (Figure 5D), which is also mediated by $\mathrm{RPTP} \beta / \zeta$ as discussed above. Bevacizumab at the same concentration significantly inhibited interaction of VEGF with VEGFR2 (Additional file 4). These data clearly indicate that although binding to VEGFR2 is essential for VEGF-induced endothelial cell migration [2], some of the angiogenic actions of VEGF, such as cell surface NCL localization, are not inhibited by bevacizumab. Taking into account that angiogenic factors, such as PTN, hepatocyte growth factor and even VEGF itself act through cell surface NCL [12], the lack of effect of bevacizumab on VEGF 165- $^{-}$ induced cell surface NCL localization may explain at least some of the cases of resistance development to bevacizumab, e.g. in glioblastomas, where classical VEGF signaling through VEGFRs has been found to remain inhibited [24]. Moreover, our data provide a mechanistic support to the notion that $\mathrm{RPTP} \beta / \zeta$ is a valuable target for glioblastoma therapies $[25,26]$.

There are two transmembrane isoforms of $\mathrm{RPTP} \beta / \zeta$, the long isoform that has been described as a CS proteoglycan, and the short isoform considered a glycoprotein. Up to date, it is still unclear which of the two RPTP $\beta / \zeta$ isoforms are responsible for each of its actions and it is not known whether glycosylation of these isoforms differs among different types of cells. Efforts to identify its CS glycanation suggest that it is regulated both developmentally and in different pathophysiological situations [27] and our unpublished observations based on Western 


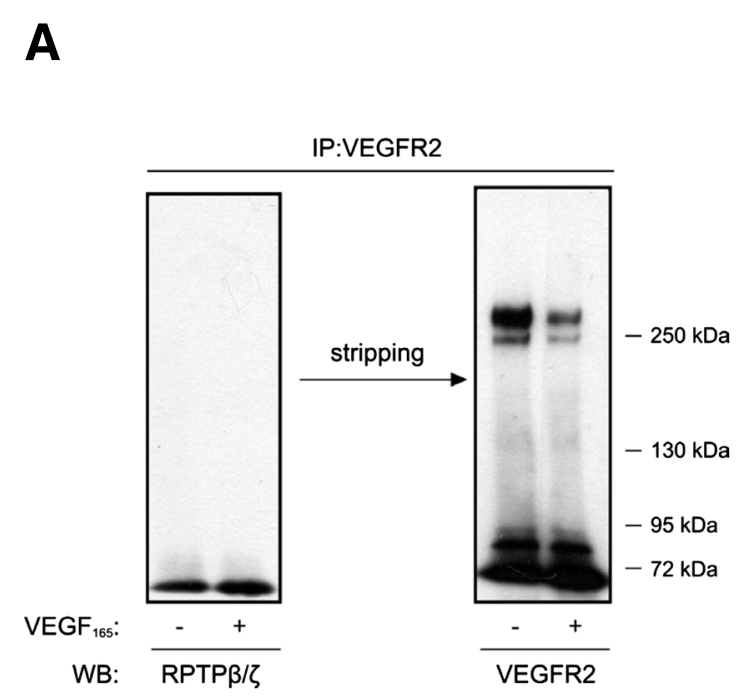

B

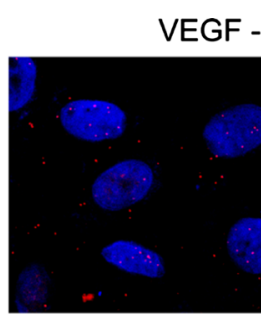

- VEGF ${ }_{165}$

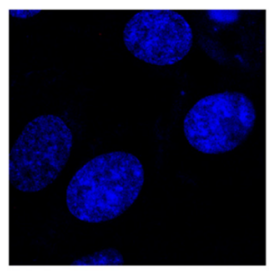

no primary antibodies

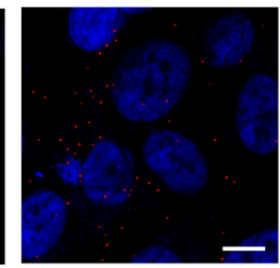

VEGF - VEGFR2

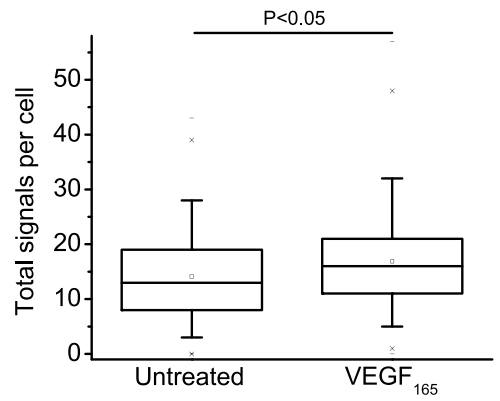

D

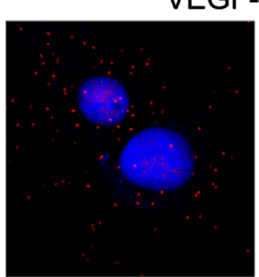

Untreated

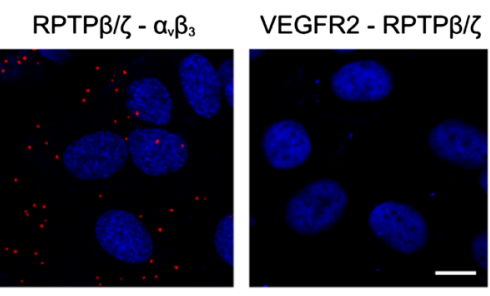

C
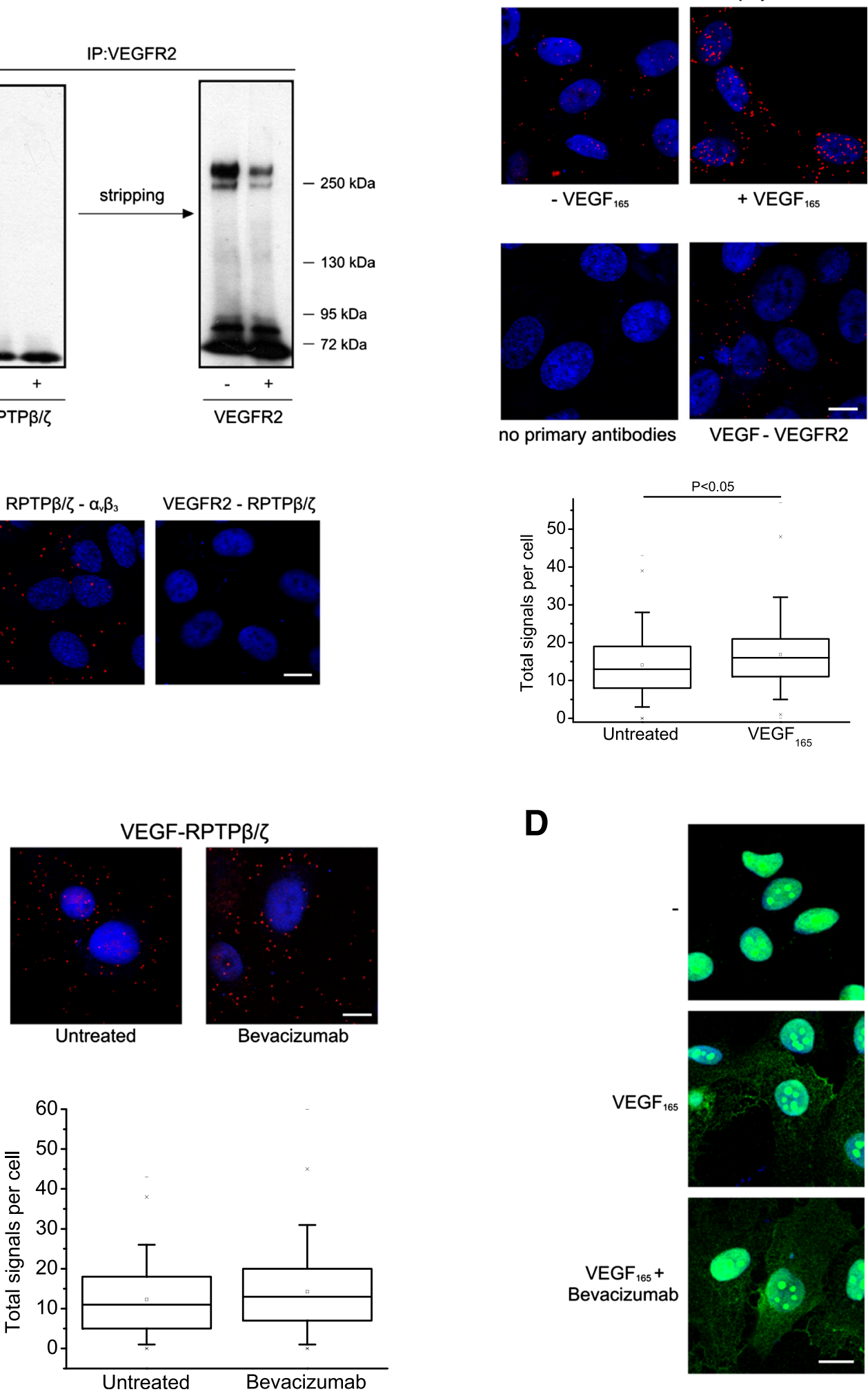

+ VEGF $_{165}$

$P<0.05$

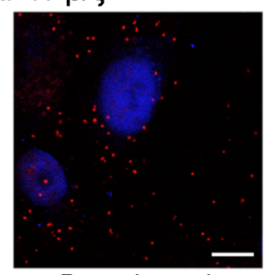

Bevacizumab

$\mathrm{VEGF}_{165}+$ Bevacizumab
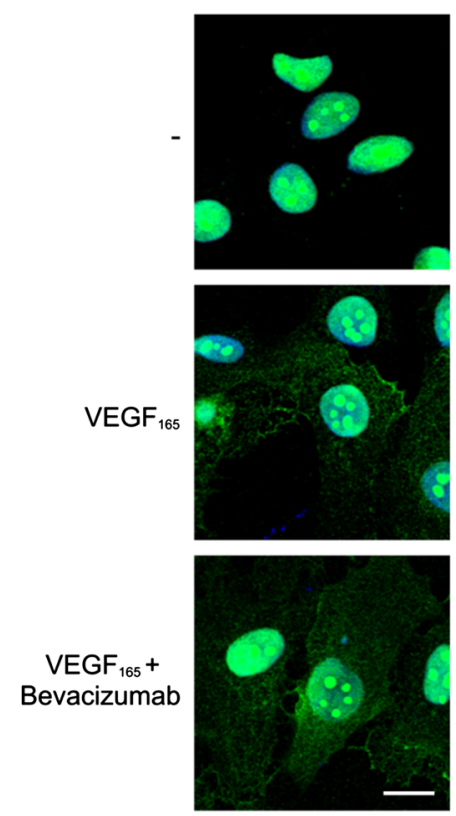
(See figure on previous page.)

Figure 5 VEGF directly interacts with RPTP $\beta / \zeta$ in a VEGFR-independent manner. (A) Serum-starved untreated or VEGF 165 -stimulated HUVEC lysates were immunoprecipitated for VEGFR2 and analyzed by Western blot for the presence of RPTP $/ \zeta$ or VEGFR2 (up). No direct interaction between VEGFR2 with RPTP $\beta / \zeta$ was observed by performing in situ PLA in HUVEC (down). The RPTP $/ \zeta$-av $\beta_{3}$ interaction was used as a positive control. Data are from two independent experiments. (B) Formation of VEGF-RPTP $\beta / \zeta$ complexes as evidenced by in situ PLA in HUVEC, untreated or after addition of exogenous VEGF $_{165}(10 \mathrm{ng} / \mathrm{ml})$ at $24 \mathrm{~h}$. The VEGF-VEGFR2 interaction was used as a positive control. Data are from five independent experiments. (C) Formation of VEGF-RPTP $\beta / \zeta$ complexes as evidenced by in situ PLA in HUVEC in the absence or the presence of bevacizumab (250 $\mu \mathrm{g} / \mathrm{ml})$. The box plots in $\mathbf{B}$ and $\mathbf{C}$ indicate the median, mean and range of the detected signals ( $n>20$ image fields with $\sim 4$ cells per image per sample type, each sample run at least in duplicate) from three independent experiments. (D) Immunofluorescence images stained for NCL (green) and nucleus (blue) in serum starved HUVEC treated for $5 \mathrm{~h}$ at $37^{\circ} \mathrm{C}$ with VEGF 165 (10 ng/ml) in the presence or the absence of bevacizumab $(250 \mu \mathrm{g} / \mathrm{ml})$. Representative pictures from three independent experiments. Scale bars in all cases correspond to $10 \mu \mathrm{m}$.

blot analyses of $\mathrm{RPTP} \beta / \zeta$ expressed in different cell types support the notion of a cell-type specific $\mathrm{RPTP} \beta / \zeta$ glycosylation. PTN binding to RPTP $\beta / \zeta$ involves both low $\left(K_{d}=3 \mathrm{nM}\right)$ and high $\left(K_{d}=0.25 \mathrm{nM}\right)$ affinity binding sites [28], which represent more than one sites of interaction that involve both the protein core and the CS chains of the receptor [5]. Oversulfation of CS is essential for PTN affinity and PTN-mediated functions [29-32], which is in line with our observation that CS-E inhibits interaction of PTN with RPTP $\beta / \zeta$ in both HUVEC and U87MG cells (Additional file 5). It should be noted, however, that although inhibition in U87MG cells was at the level of $70 \%$ (total signals per cell in control: $23 \pm 7$ and in CS-E treated cells: $8 \pm 1$ ), in HUVEC it was smaller, at the level of $50 \%$ (total signals per cell in control: $6 \pm 0.4$ and in CS-E treated cells: $3 \pm 0.3$ ).

Since VEGF has been shown to be able to bind to CSE similarly to heparan sulphate, but does not bind CS-C or CS-A [33], we investigated whether CS-E also inhibits VEGF interaction with $\mathrm{RPTP} \beta / \zeta$. CS-E decreased interaction of VEGF with RPTP $\beta / \zeta$ in U87MG cells (Additional file 6), but had no effect on HUVEC (Figure 6A), in line with the observation that it did not affect $\mathrm{VEGF}_{165}$-induced cell surface NCL localization (Figure 6B). This difference could be explained by the hypothesis that cell surface NCL localization depends on the interaction of VEGF with the short, non-proteoglycan isoform of RPTP $\beta / \zeta$. Interestingly and in favor of such a possibility, in U87MG cells that express higher amounts of endogenous VEGF than HUVEC, we performed IP/Western blot assays and observed that CS-E inhibits interaction of both PTN and VEGF with the long, but not the short RPTP $\beta / \zeta$ isoform (Additional file 6). These data suggest that interaction of VEGF (and PTN) with the short RPTP $\beta / \zeta$ isoform may not involve CS-E chains. On the other hand, CS-E abolished $\mathrm{VEGF}_{165^{-}}$ induced HUVEC migration (Figure 6C), an effect that may involve a different cell surface molecule or parallel signaling pathways that are important for cell migration. This point is under further investigation.

The idea that the interaction of VEGF with $\mathrm{RPTP} \beta / \zeta$ does not involve its heparin-binding properties is further supported by the observation that $\mathrm{VEGF}_{121}$, which induces HUVEC migration but does not contain the heparin-binding site of VEGF [34], also induces cell surface NCL localization (Figure 6D). Collectively, our data suggest that interaction of VEGF with $\mathrm{RPTP} \beta / \zeta$ may involve a part of the molecule that is distinct from those involved in VEGFR or glycosaminoglycan binding. This notion is similar to the recent finding that the high affinity neuropilin-1 binding of VEGF-A involves the exon 8-encoded C-terminal Arg [35]. Tuftsin, a naturally occurring TKPR peptide with sequence similarity to the sequence coded by exon 8 of VEGF, blocks VEGF $165^{-}$ induced autophosphorylation of VEGFR2, without inhibiting VEGF binding to VEGFR2 [36]. Taking into account that PTN binding to $\mathrm{RPTP} \beta / \zeta$ involves PTN's carboxy terminal region that is rich in basic amino acids [37], and that PTN inhibits VEGF binding to RPTP $\beta / \zeta$ (see below), one can speculate that binding of VEGF to RPTP $\beta / \zeta$ might be mediated by its exon 8 -encoded sequence.

Finally, we found that the interaction of VEGF with $\mathrm{RPTP} \beta / \zeta$ was decreased in the presence of PTN in both HUVEC (Figure 7A) and U87MG cells (Additional file 7 ), suggesting that these two growth factors share a common binding site on $\mathrm{RPTP} \beta / \zeta$. This is further supported by the observation that the PTN-RPTP $\beta / \zeta$ interaction was also decreased in the presence of exogenous VEGF $_{165}$ (Figure 7B). It has been previously suggested that besides the CS chains, the core $\mathrm{RPTP} \beta / \zeta$ protein is also involved in binding to PTN $[28,38]$, which may also be the site of interaction of the short $\mathrm{RPTP} \beta / \zeta$ transmembrane isoform with VEGF, as discussed above.

PTN stimulates human endothelial cell migration by approximately $40 \%[6,8,11]$, an effect that is smaller than that of other growth factors, such as VEGF. Interestingly, PTN decreased VEGF 165 -induced HUVEC migration to the levels of its own, smaller stimulatory effect (Figure 7C), in agreement with a previous study showing that PTN did not abolish but decreased $\mathrm{VEGF}_{165}$-induced endothelial cell infiltration of matrigel in vivo to the levels of its own stimulation [39]. These data favor the notion that PTN and VEGF compete for binding to $\mathrm{RPTP} \beta / \zeta$, as 


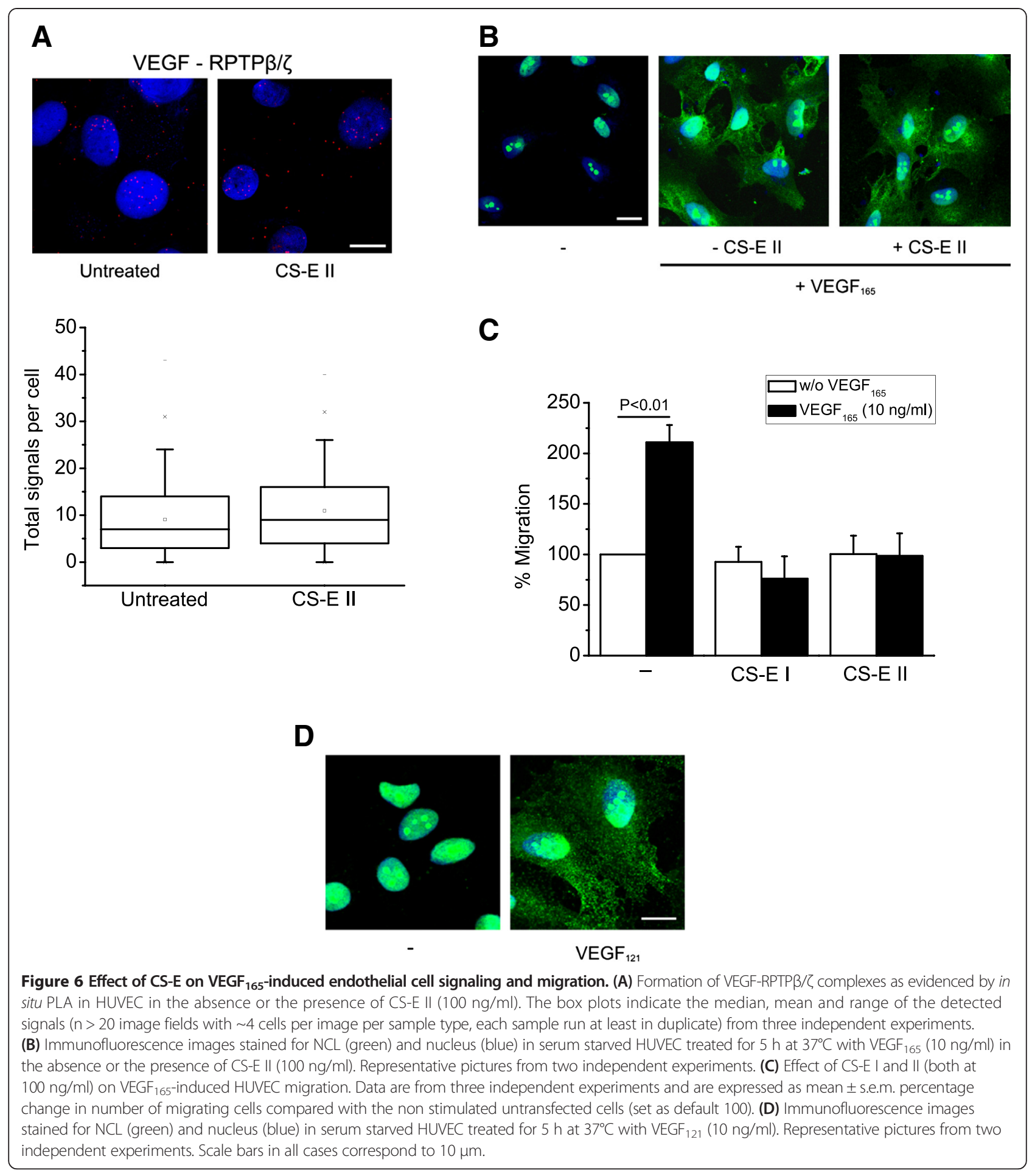

discussed above, and highlight a possible role for PTN as a regulator of angiogenesis, by limiting the aberrant effect of VEGF, while it still induces a smaller, significant stimulatory effect.

It is important to note that although $\mathrm{RPTP} \beta / \zeta$ is required for cell migration induced by PTN [6] and $\mathrm{VEGF}_{165}$ (present study), it is not sufficient by itself to induce cell migration, based on our previous data showing that midkine [8] or PTN $\mathrm{PT}_{112-136}$ [40], which lead to c-Src Tyr530 dephosphorylation and $\beta_{3}$ Tyr773 phosphorylation through $\mathrm{RPTP} \beta / \zeta$, do not induce endothelial cell migration. It seems that other receptors/signaling pathways are activated 


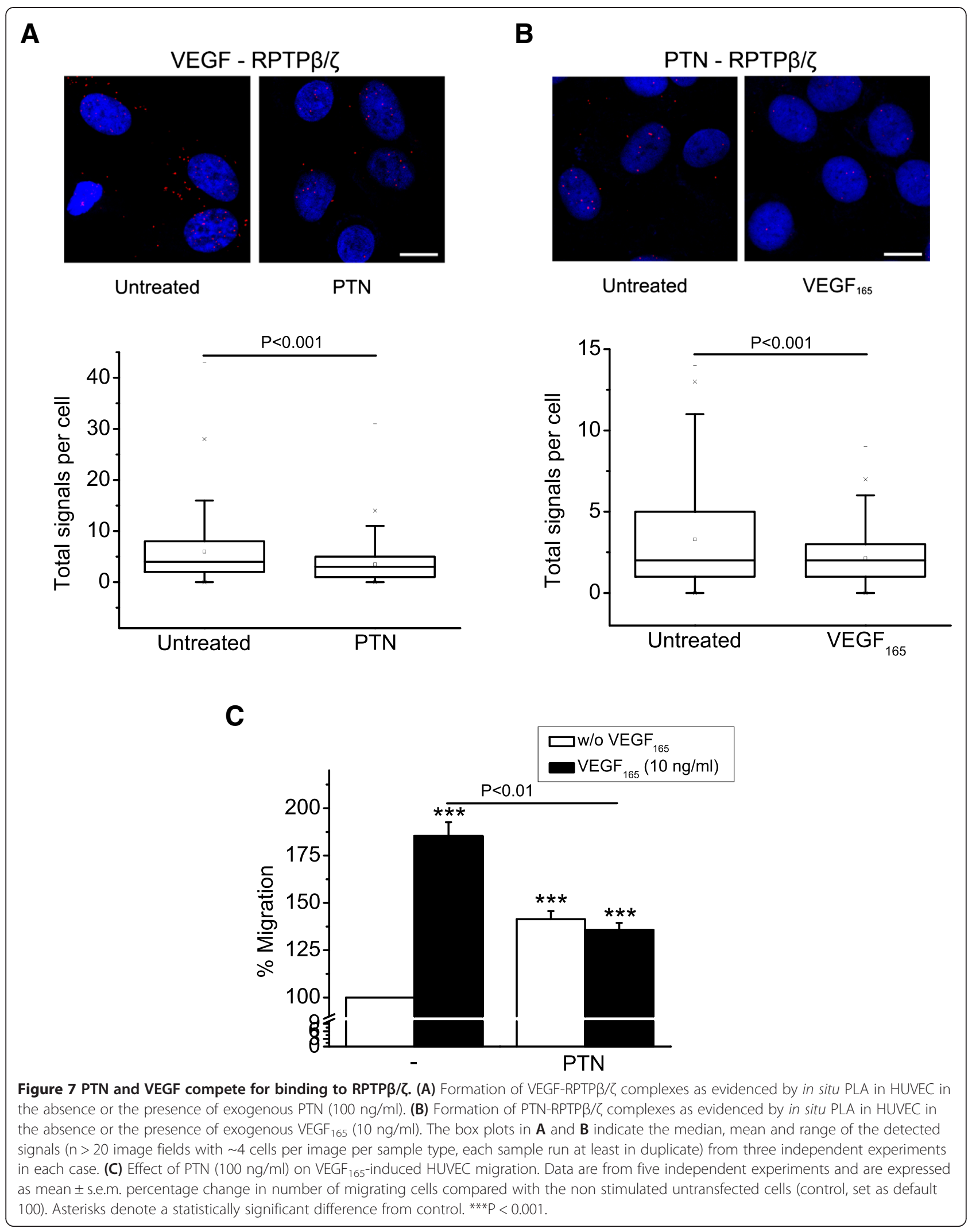


in parallel with the RPTP $\beta / \zeta / c-S r c / \alpha_{v} \beta_{3}$ pathway to complementarily induce cell migration. Such a pathway for VEGF $_{165}$ involves at least VEGFR2 and the cross-talk of signaling molecules activated by $\mathrm{VEGF}_{165}$ through $\mathrm{RPTP} \beta / \zeta$, $\alpha_{v} \beta_{3}$ and VEGFR2 or other cell surface binding molecules in different cell types is under further investigation.

\section{Conclusion}

$\mathrm{RPTP} \beta / \zeta$ is a receptor-type protein tyrosine phosphatase expressed in several types of cancer and involved in cell migration, cancer progression and metastasis $[5,27]$. The current study identifies $\mathrm{RPTP} \beta / \zeta$ as a novel cell membrane binding molecule for $\operatorname{VEGF}_{165}$, which regulates cSrc-mediated $\beta_{3}$ Tyr773 phosphorylation and interaction with VEGFR2, cell surface NCL localization through PI3K activation and endothelial cell migration (Figure 8). These data are of high significance, especially taking into account that the interaction of VEGF with RPTP $\beta / \zeta$ and the downstream angiogenic VEGF actions, such as cell surface NCL localization, do not seem to be affected by existing anti-VEGF drugs, such as bevacizumab, and may explain the resistance developed by tumor types, e.g. glioblastoma, in such therapies $[24,41]$. They thus warrant exploitation of RPTP $\beta / \zeta$ for the possible development of alternative or additive anti-angiogenic therapies, especially in cases where resistance develops.

\section{Methods}

\section{Materials}

Human recombinant $\mathrm{VEGF}_{165}$ was prepared as previously described [39]. VEGF 121 was purchased from RELIATech $\mathrm{GmbH}$ (Wolfenbüttel, Germany). Bevacizumab (AVASTIN) was from Roche Applied Science (Indianapolis, IN, USA). Human recombinant PTN was from PeproTech, Inc. (Rocky Hill, NJ, USA) or prepared as previously described [39]. PTN from both sources was equally active in all cases. CS-E was either from Seikagaku Corporation (Tokyo, Japan) (CS-E I), or prepared from a crude preparation of squid cartilage CS (purchased from Yantai Changsen Chemical Co., Ltd., Shandong, China) (CS-E II), both sources being equally active. PP1, wortmannin and U0126 were from TOCRIS (Minneapolis, MN, USA) and SU1498 was from Santa Cruz Biotechnology Inc. (Santa Cruz, CA, USA). All secondary horseradish peroxidase-conjugated antibodies were from Cell Signaling Technology Inc. (Beverly, MA, USA). Human IgG and other reagents were from Sigma (St. Louis, MO, USA).

\section{Cell culture}

HUVEC, human glioma U87MG cells and $\mathrm{CHO}$ cells expressing $\alpha_{v}$ but deficient in endogenous $\beta_{3}$ integrin or stably transfected to express wild type $\beta_{3}, \beta_{3}$ Y773F, $\beta_{3} \mathrm{Y} 785 \mathrm{~F}$ or $\beta_{3} Y 773 F / Y 785 F$ were cultured as previously described

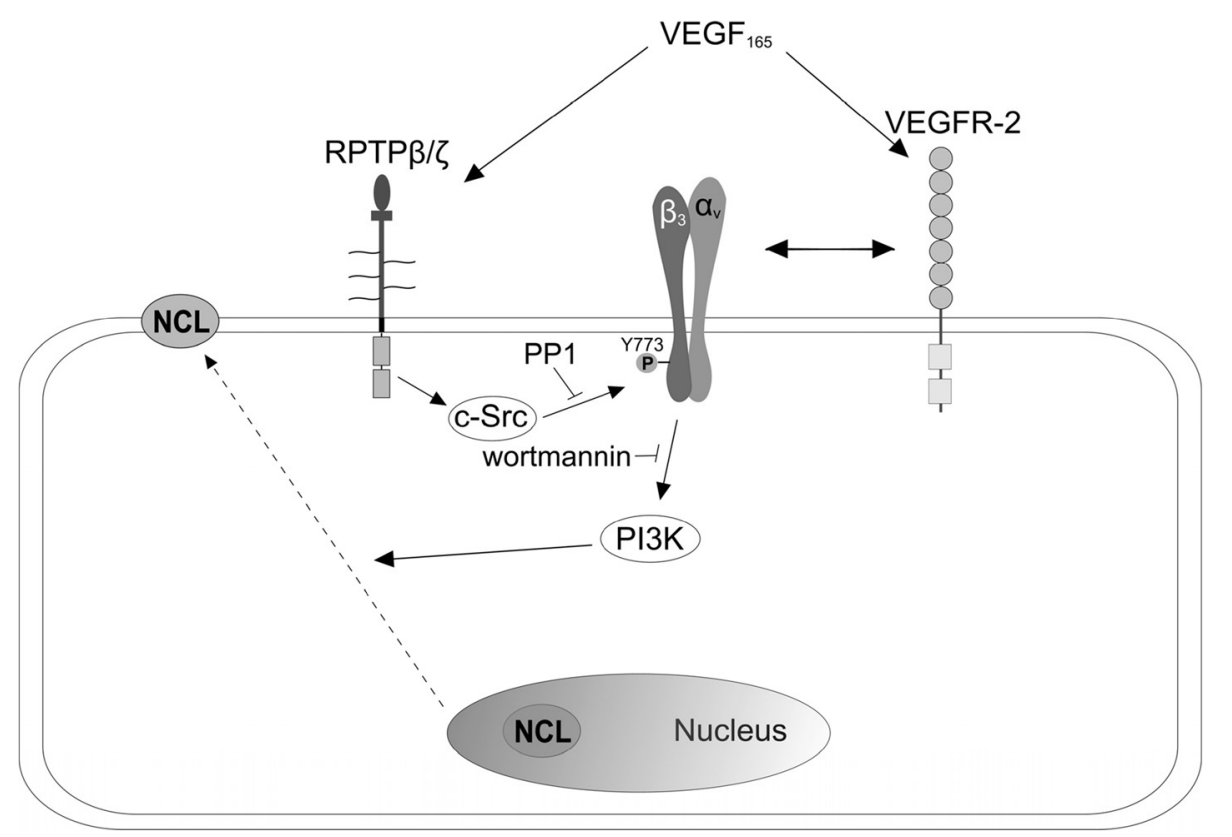

Figure 8 Schematic representation of the proposed mechanism that involves RPTP $\beta / \zeta$ and leads to increased $\alpha_{v} \beta_{3}$-VEGFR2 interaction, cell surface NCL localization and stimulation of cell migration by VEGF. Binding of VEGF 165 to RPTP $\beta / \zeta$ on the surface of endothelial or cancer cells leads to $c$-Src activation, $\beta_{3}$ Tyr773 phosphorylation and increased interaction of $\alpha_{v} \beta_{3}$ with VEGFR2, as well as PI3K activation and translocation of NCL from the nucleus to the cell membrane. Both are required for $\mathrm{VEGF}_{165}$-induced endothelial cell migration. For more details see text. 
[8,11]. Cell culture reagents were from BiochromKG (Seromed, Germany). All cultures were maintained at $37^{\circ} \mathrm{C}, 5 \% \mathrm{CO}_{2}$, and $100 \%$ humidity. When cells reached $70-80 \%$ confluence, they were serum starved for $16 \mathrm{~h}$ (where indicated) before performing migration assays, lysed for immunoprecipitation/Western blot assays or fixed for immunofluorescence assays and in situ PLA.

\section{Immunofluorescence}

Cells were fixed with $4 \%$ formaldehyde in phosphatebuffered saline (PBS) $\mathrm{pH} 7.4$ for $10 \mathrm{~min}$ and permeabilized with $0.1 \%$ Triton in PBS for 15 min. After being washed 3 times with PBS, the cells were blocked with PBS containing 3\% BSA and 10\% fetal bovine serum (FBS) for $1 \mathrm{~h}$ at room temperature. Cells were stained with the following primary antibodies: rabbit anti-VEGF (1:250; Santa Cruz Biotechnology Inc.), mouse antiRPTP $\beta / \zeta$ (1:250; BD Biosciences, San Diego, CA, USA), mouse anti- $\alpha_{v} \beta_{3}$ (1:500; Merck Millipore, Darmstadt, Germany), and rabbit anti-NCL (1:1,000, Sigma). Cells were then incubated with fluorescent Alexa secondary antibodies (1:500; Molecular Probes, Carlsbad, CA, USA). Nuclei were stained with Draq5 (Biostatus Limited, Leicestershire, UK). Cells were mounted with Mowiol 4-88 (Merck Millipore) and visualized at room temperature with Leica SP5 (X63 objective with a numerical aperture of 1.4) confocal microscope.

\section{In situ PLA}

For detection of protein-protein interactions, in situ PLA was performed. The components used (Sigma) were as follows: anti-mouse PLA plus probe, anti-rabbit PLA minus probe and Detection Reagents Orange. HUVEC or U87MG cells were grown on $\mu$-Chamber 12 well on glass slides (Ibidi@), Martinsried, Germany). After reaching $80 \%$ confluence or after appropriate treatment of cells, the assay was performed according to the manufacturer's instructions. Briefly, after fixation and blocking, cells were incubated with the primary antibodies: mouse antiVEGF (1:250), rabbit anti-VEGF (1:250), rabbit anti-Flk-1 (1:250), mouse anti-Flk-1 (1:250), mouse anti-NCL (1:50), goat anti-RPTP $\beta / \zeta$ (1:250) (all from Santa Cruz Biotechnology Inc.), mouse anti- $\alpha_{v} \beta_{3}$ (1:500; Merck Millipore), mouse anti-PTN (1:500; Abnova, Heidelberg, Germany) and mouse anti-RPTP $\beta / \zeta$ (1:250; BD Biosciences). Subsequently, cells were incubated with secondary antibodies conjugated with oligonucleotides. After hybridization and ligation of the oligonucleotides, the DNA was amplified. A detection mixture detected the amplicons, resulting in red fluorescence signals. Nuclei were counterstained with Draq5; cells were mounted with Mowiol 4-88 and visualized at room temperature with Leica SP5 confocal microscope.

\section{Quantification of in situ PLA signals}

Estimation of nuclei and cytoplasm size was performed using the Duolink ImageTool software (Olink Bioscience). In order to calculate the total number of spots per cell, an algorithmic procedure was developed and implemented in the Matlab environment (The MathWorks Inc., Massachusetts, USA). "I" denotes an immunofluorescence image of $\mathrm{m} \times \mathrm{n}$ size. Such an image can be seen as a "stack" of three matrices of the same size; representing the red, green and blue values for each pixel indicated as IR, IG, IB for the three color bands, respectively. For every pixel at position (i, j) correspond three values; $\operatorname{IR}(i, j), I G(i, j), I B(i, j)$, ranging from 0 to 255 . Image pre-processing was performed to identify pixels of red intensities less than a determined threshold value $\theta$, in order to exclude background noise. Several values were tested and evaluated and finally $\theta$ was set to 50 . In order to detect a red dot, the algorithm searches the red band (i.e., the IR matrix) for a group of at least $\mathrm{c}$ connected pixels. The value of the parameter $\mathrm{c}$, which controls the minimum number of pixels that constitute a dot, c was set to 10. Moreover, in the case of overlapping dots, large groups of pixels were identified. In such cases, the true number of dots was calculated as [n/100] since a typical dot contains approximately 100 pixels, where $n$ is the total number of pixels of the initial group and the operator $[\alpha]$ is used to round the number $\alpha$ into its nearest integer.

\section{RNA interference}

Cells were grown to $50 \%$ confluence in medium without antibiotics. Transfection was performed in serum-free medium for $4 \mathrm{~h}$ using annealed RNA for RPTP $\beta / \zeta$ (siRPTP $\beta / \zeta \# 1$, VBC Biotech Services, Vienna, Austria), as previously described [6]. Another siRNA sequence for RPTP $\beta / \zeta$ (siRPTP $\beta / \zeta \# 2$, Hs_PTPRZ1_1 FlexiTube siRNA, Qiagen $\mathrm{GmbH}$, Germany) was also used as a control for off-target effects. JetSI-ENDO (Polyplus Transfection, Illkirch, France) or Lipofectamine ${ }^{\bullet}$ RNAiMAX (Life Technologies) were used as transfection reagents. Double-stranded negative control siRNA (Ambion, Austin, TX, USA) was used in all experiments. Cells were incubated for another $48 \mathrm{~h}$ in serum-containing medium and lysed, serum starved or fixed before further experiments.

\section{Migration assays}

Migration assays were performed as previously described $[8,11]$ in 24-well microchemotaxis chambers (Corning, Inc., Lowell, MA, USA) using uncoated polycarbonate membranes with $8 \mu \mathrm{m}$ pores. Serum-starved cells were harvested, resuspended at a concentration of $10^{5}$ cells $/ 0.1 \mathrm{ml}$ in serum-free medium containing $0.25 \%$ bovine serum albumin (BSA) and loaded in the 
upper chamber. The bottom chamber was filled with $0.6 \mathrm{ml}$ of serum-free medium containing $0.25 \%$ BSA and the tested substances. Cells were incubated for $4 \mathrm{~h}$ at $37^{\circ} \mathrm{C}$. After completion of the incubation, filters were fixed and stained with $0.33 \%$ toluidine blue solution. The cells that migrated through the filters were quantified by counting the entire area of each filter, using a grid and a microscope with a X20 objective (Optech Microscope Services Ltd., Thames, UK).

\section{PI3K p85 ELISA}

The levels of total and phosphorylated PI3K p85 were quantified using Fast Activated Cell-based ELISA assays (Active Motif, Carlsbad, CA, USA) according to the manufacturer's instructions. Briefly, cells were cultured in 96-well plates one day prior to manipulation. Serum starved $\mathrm{CHO}$ cells or HUVEC were treated with $10 \mathrm{ng} /$ $\mathrm{ml} \mathrm{VEGF} 165$ for $10 \mathrm{~min}$ (in the presence or absence of inhibitors of signaling molecules where appropriate), fixed and incubated with anti-phospho and anti-total p85 antibodies.

\section{Immunoprecipitation assay}

Cells were lysed with RIPA buffer, as previously described [8]. Three $\mathrm{mg}$ of total protein were incubated with primary antibody for $16 \mathrm{~h}$ at $4^{\circ} \mathrm{C}$ under continuous agitation. The primary antibodies used were: mouse anti-VEGF $(3 \mu \mathrm{g})$, mouse anti-Flk-1 $(3 \mu \mathrm{g})$, goat anti-RPTP $\beta / \zeta(3 \mu \mathrm{g})$, goat anti-PTN (3 $\mu \mathrm{g})$ (Santa Cruz Biotechnology Inc.) and goat anti- $\beta_{3}(1.5 \mu \mathrm{g}$; Merck Millipore). Protein A- and protein G-agarose beads (Merck Millipore) were added, samples were further incubated for $2 \mathrm{~h}$ at $4^{\circ} \mathrm{C}$, and beads with bound proteins were collected by centrifugation $(5,000 \mathrm{~g}$ for $5 \mathrm{~min}$ at $4^{\circ} \mathrm{C}$ ) and washed twice with ice-cold PBS $\mathrm{pH}$ 7.4. Immunoprecipitated proteins were resuspended in SDS loading buffer and analyzed by Western blot.

\section{Western blot analysis}

Proteins were analyzed by SDS-PAGE and transferred to Immobilon P membranes. Blocking was performed by incubating the membranes with Tris-buffered saline (TBS) $\mathrm{pH} 7.4$ with $0.05 \%$ Tween (TBS-T), containing either 5\% nonfat dry milk or 3\% BSA. Membranes were incubated with primary antibodies for $16 \mathrm{~h}$ at $4^{\circ} \mathrm{C}$ under continuous agitation, washed 3 times with TBS-T, and incubated with secondary antibodies for $1 \mathrm{~h}$ at room temperature. Primary antibodies used were mouse anti-Flk-1 (1:500), goat anti- $\beta_{3}$ (1:500), mouse anti-VEGF (1:500), rabbit antiphospho- $\beta_{3}(\mathrm{Y} 773) \quad(1: 1,000$; Santa Cruz Biotechnology Inc.), mouse anti-RPTP $\beta / \zeta$ (1:500; BD Biosciences), rabbit anti-c-Src (1:1,000; Merck Millipore), rabbit anti-phosphoc-Src(Y418) (1:1,000; Acris Antibodies GmbH) and rabbit anti-non-phospho-c-Src (1:1,000; Cell Signaling Technology Inc.). Detection of immunoreactive bands was performed using the enhanced chemiluminescence detection kit (Pierce Biotechnology, Rockford, IL, USA). Protein levels were quantified using the ImagePC image analysis software (Scion Corp., Frederick, MD, USA).

\section{Statistical analysis}

Results are expressed as mean \pm s.e.m. or by using box plots, where the box is determined by the $25^{\text {th }}$ and $75^{\text {th }}$ percentiles, the whiskers are determined by the $5^{\text {th }}$ and $95^{\text {th }}$ percentiles, the line in the box marks the median and the empty square in the box marks the mean. Outliers have been plotted as individual points. Where applicable, variability between the results from each group and the corresponding control was determined by unpaired $t$ test.

\section{Additional files}

Additional file 1: c-Src activation may be independent of VEGFVEGFR2 interaction. Serum starved HUVEC were treated with VEGF 165 (10 $\mathrm{ng} / \mathrm{ml}$ ) for $10 \mathrm{~min}$ in the presence or absence of either the selective VEGFR2 tyrosine kinase inhibitor SU1498 $(10 \mu \mathrm{M})$ or bevacizumab $(250 \mu \mathrm{g} / \mathrm{ml})$. Cell lysates were analyzed by Western blot for non Tyr530 phosphorylated (npc-Src), Tyr419 phosphorylated (pc-Src) and total (tc-Src) c-Src. Numbers in brackets denote the average-fold change of the ratio npc-Src:tc-Src or pc-Src:tc-Src respectively, compared with the corresponding non stimulated, untransfected cells (set as default 1) from three independent experiments.

Additional file 2: VEGF-RPTP $\beta / \zeta$ interaction in human glioma U87MG cells. (A) Immunofluorescence images of HUVEC and U87MG cells stained for VEGF (green) and nucleus (blue). Representative pictures from three and two independent experiments respectively. (B) U87MG cell lysates were immunoprecipitated for RPTP $\beta / \zeta$ or VEGF. Immunoprecipitates were analyzed by Western blot for the presence of VEGF or RPTP $\beta / \zeta$, respectively. IgG was used as a negative control. Representative blots from two independent experiments. (C) Immunofluorescence images of U87MG cells stained for VEGF (green), RPTP $\beta / \zeta$ (red) and nucleus (blue). Representative pictures from two independent experiments. (D) In situ PLA signals were detected as red dots, indicating the direct formation of VEGF- RPTP $\beta / \zeta$ complexes. Representative pictures from three independent experiments. Scale bars in $A, C$ and D correspond to $10 \mu \mathrm{m}$. (E) Formation of VEGF-RPTP $\beta / \zeta$ complexes as evidenced by in situ PLA in HUVEC and U87MG cells. The box plots indicate the median, mean and range of the detected signals ( $n>20$ image fields with 4-6 cells per image per sample type, each sample run in duplicate) from four independent experiments.

Additional file 3: VEGF does not interact with $\alpha_{v} \beta_{3}$. (A) Immunofluorescence images of U87MG cells cultured in serum-containing medium and stained for VEGF (green), $a_{v} \beta_{3}$ (red) and nucleus (blue). Representative pictures from two independent experiments. (B) The absence of in situ PLA signals indicates lack of the VEGF- $a_{v} \beta_{3}$ direct interaction in both HUVEC and U87MG cells. The PTN- $\alpha_{v} \beta_{3}$ interaction in both types of cells was used as a positive control. Representative pictures from two independent experiments.

Additional file 4: Bevacizumab inhibits VEGF-VEGFR2 interaction. Formation of VEGF-VEGFR2 complexes as evidenced by in situ PLA in HUVEC in the absence or the presence of bevacizumab $(250 \mu \mathrm{g} / \mathrm{ml})$. The box plots indicate the median, mean and range of the detected signals ( $n>20$ image fields with $\sim 4$ cells per image per sample type, each sample run at least in duplicate) from two independent experiments. Scale bars in all cases correspond to $10 \mu \mathrm{m}$.

Additional file 5: CS-E inhibits PTN-RPTP $\beta / \zeta$ interaction in both HUVEC and U87MG cells. Formation of PTN-RPTP $\beta / \zeta$ complexes as evidenced by in situ PLA in HUVEC (A) and U87MG cells (B) in the absence or presence of CS-E II $(100 \mathrm{ng} / \mathrm{ml})$. The box plots indicate the median, mean and range of 
the detected signals ( $n=20$ image fields with $\sim 6$ cells per image per sample type, each sample run in duplicate) from four (A) and three (B) independent experiments. Scale bars in all cases correspond to $10 \mu \mathrm{m}$.

\section{Additional file 6: CS-E inhibits VEGF-RPTP $\beta / \zeta$ interaction in U87MG} cells. (A) Formation of VEGF-RPTP $\beta / \zeta$ complexes as evidenced by in situ PLA in U87MG cells in the absence or presence of CS-E II (100 ng/ml). The box plots indicate the median, mean and range of the detected signals $(n=8$ image fields with $\sim 4$ cells per image per sample type, each sample run in duplicate) from three independent experiments. Scale bar corresponds to $10 \mu \mathrm{m}$. (B) U87MG cell lysates were immunoprecipitated for VEGF. Immunoprecipitates were analyzed by Western blot for the presence of RPTP $\beta /$ C. (C) U87MG cell lysates were immunoprecipitated for PTN. Immunoprecipitates were analyzed by Western blot for the presence of RPTP $\beta / \zeta$. In B and C, representative blots from two independent experiments are shown.

\section{Additional file 7: PTN inhibits VEGF-RPTP $\beta /$ / interaction in U87MG}

cells. (A) Formation of VEGF-RPTP $\beta / \zeta$ complexes as evidenced by in situ PLA in U87MG cells in the absence or presence of PTN $(100 \mathrm{ng} / \mathrm{ml})$. The box plots indicate the median, mean and range of the detected signals ( $n=6$ image fields with $\sim 5$ cells per image per sample type, each sample run in duplicate). Scale bar corresponds to $10 \mu \mathrm{m}$. Data come from three independent experiments. (B) Cell lysates were immunoprecipitated for RPTP $\beta / \zeta$. Immunoprecipitates were analyzed by Western blot for the presence of VEGF. IgG was used as a negative control. Representative blots from two independent experiments.

\section{Abbreviations}

BSA: Bovine serum albumin; CS: Chondroitin sulphate; ELISA: Enzyme-linked immunoassay; FBS: Fetal bovine serum; NCL: Nucleolin; PBS: Phosphate buffered saline; PI3K: Phosphatidylinositol 3-kinase; PLA: Proximity ligation assay; PTN: Pleiotrophin; RPTP $\beta /$ /: Receptor protein tyrosine phosphatase beta/zeta; TBS: Tris-buffered saline; VEGF: Vascular endothelial growth factor; VEGFR2: Vascular endothelial growth factor receptor 2.

\section{Competing interests}

The authors declare that they have no competing interests.

\section{Authors' contributions}

MK, EPo and EPap participated in research design. MK and EPa performed PLA assays and EPa, AS and VM contributed analytical tools for PLA signal quantification. MK, EPo, EPa and CT performed immunoprecipitation/Western blot assays. SM and KS prepared CS-E and provided expertise on CS. NK provided stably transfected cell lines and expertise on integrins. JC contributed new analytic tools. MK, EPo, EPa, CT, AS and EPap performed data analysis. All authors contributed to the writing of the manuscript. All authors read and approved the manuscript.

\section{Acknowledgements}

This work was supported by the European Union (European Social Fund ESF, Heracleitus II (to M. Koutsioumpa - E. Papadimitriou), Thales (to V. Megalooikonomou) and IKY Fellowship of Excellence for Postgraduate studies in Greece - Siemens Program (to E. Pantazaka). This work was also supported in part by a Grant-in-Aid for Scientific Research for Challenging Exploratory Research 25670018 (to K. Sugahara) from the Japan Society for the Promotion of Science (JSPS). The authors thank the Advanced Light Microscopy facility of the Medical School, University of Patras for using the Leica SP5 confocal microscope and the PhD candidate Margarita Lamprou for technical support.

\section{Author details}

'Laboratory of Molecular Pharmacology, Department of Pharmacy, University of Patras, GR 26504 Patras, Greece. ${ }^{2}$ Computer Engineering and Informatics Department, University of Patras, GR 26504 Patras, Greece. ${ }^{3}$ Sino-French Research Centre for Life Sciences and Genomics, CNRS/LIA124, Rui Jin Hospital, Jiao Tong University Medical School, Shanghai, China. ${ }^{4}$ Laboratoire CRRET, Universite Paris Est Creteil Val de Marne, Paris, France. ${ }^{5}$ Proteoglycan Signaling and Therapeutics Research Group, Faculty of Advanced Life Science, Hokkaido University, Sapporo, Japan. ${ }^{6}$ Current address: Center for Systems Biomedicine, Division of Digestive Diseases, David Geffen School of Medicine, University of California Los Angeles, Los Angeles, CA, USA. ${ }^{7}$ Current address: Department of Pathobiochemistry, Faculty of Pharmacy, Meijo University, Nagoya 463-8503, Japan.

Received: 22 May 2014 Accepted: 2 January 2015 Published online: 03 February 2015

\section{References}

1. Koch S, Claesson-Welsh L. Signal transduction by vascular endothelial growth factor receptors. Cold Spring Harb Perspect Med. 2012;2:a006502.

2. Mahabeleshwar GH, Feng W, Reddy K, Plow EF, Byzova TV. Mechanisms of integrin-vascular endothelial growth factor receptor cross-activation in angiogenesis. Circ Res. 2007;101:570-80.

3. Somanath PR, Malinin NL, Byzova TV. Cooperation between integrin alphavbeta3 and VEGFR2 in angiogenesis. Angiogenesis. 2009;12:177-85.

4. Ingley E. Src family kinases: regulation of their activities, levels and identification of new pathways. Biochim Biophys Acta. 2008;1784:56-65.

5. Koutsioumpa M, Papadimitriou E: PG receptors with phosphatase action in cancer and angiogenesis. In Extracellular Matrix: Pathobiology and Signalling. Edited by Karamanos N. Berlin/Boston: Walter de Gruyter GmbH and Co KG; 2012:813-823.

6. Polykratis A, Katsoris P, Courty J, Papadimitriou E. Characterization of heparin affin regulatory peptide signaling in human endothelial cells. J Biol Chem. 2005;280:22454-61.

7. Papadimitriou E, Mikelis C, Lampropoulou E, Koutsioumpa M, Theochari K, Tsirmoula S, et al. Roles of pleiotrophin in tumor growth and angiogenesis. Eur Cytokine Netw. 2009;20:180-90.

8. Mikelis C, Sfaelou E, Koutsioumpa M, Kieffer N, Papadimitriou E. Integrin alpha(v)beta(3) is a pleiotrophin receptor required for pleiotrophin-induced endothelial cell migration through receptor protein tyrosine phosphatase beta/zeta. FASEB J. 2009;23:1459-69.

9. Fujikawa A, Shirasaka D, Yamamoto S, Ota H, Yahiro K, Fukada M, et al. Mice deficient in protein tyrosine phosphatase receptor type $Z$ are resistant to gastric ulcer induction by VacA of Helicobacter pylori. Nat Genet. 2003;33:375-81.

10. Nandi S, Cioce M, Yeung YG, Nieves E, Tesfa L, Lin H, et al. Receptor-type protein-tyrosine phosphatase $\zeta$ is a functional receptor for interleukin-34. J Biol Chem. 2013;288:21972-86.

11. Koutsioumpa M, Polytarchou C, Courty J, Zhang Y, Kieffer N, Mikelis C, et al. Interplay between $a_{v} \beta_{3}$ integrin and nucleolin regulates human endothelial and glioma cell migration. J Biol Chem. 2013;288:343-54.

12. Koutsioumpa M, Papadimitriou E. Cell surface nucleolin as a target for anticancer therapies. Recent Pat Anticancer Drug Discov. 2014;9:137-52.

13. Huang $Y$, Shi H, Zhou H, Song X, Yuan S, Luo Y. The angiogenic function of nucleolin is mediated by vascular endothelial growth factor and nonmuscle myosin. Blood. 2006;107:3564-71.

14. Destouches D, El Khoury D, Hamma-Kourbali Y, Krust B, Albanese P, Katsoris P, et al. Suppression of tumor growth and angiogenesis by a specific antagonist of the cell-surface expressed nucleolin. PLoS One. 2008;3:e2518.

15. Barel M, Le Romancer M, Frade R. Activation of the EBV/C3d receptor (CR2, CD21) on human B lymphocyte surface triggers tyrosine phosphorylation of the 95-kDa nucleolin and its interaction with phosphatidylinositol 3 kinase. J Immunol. 2001;166:3167-73.

16. Wu DM, Zhang P, Liu RY, Sang YX, Zhou C, Xu GC, et al. Phosphorylation and changes in the distribution of nucleolin promote tumor metastasis via the PI3KJAkt pathway in colorectal carcinoma. FEBS Lett. 2014;588:1921-9.

17. Hovanessian AG, Puvion-Dutilleul F, Nisole S, Svab J, Perret E, Deng JS, et al. The cell-surface-expressed nucleolin is associated with the actin cytoskeleton. Exp Cell Res. 2000;261:312-28.

18. Spiro DJ, Boll W, Kirchhausen T, Wessling-Resnick M. Wortmannin alters the transferrin receptor endocytic pathway in vivo and in vitro. Mol Biol Cell. 1996;7:355-67.

19. Thong FS, Dugani CB, Klip A. Turning signals on and off: GLUT4 traffic in the insulin-signaling highway. Physiology (Bethesda). 2005;20:271-84.

20. Abe M, Setoguchi Y, Tanaka T, Awano W, Takahashi K, Ueda R, et al. Membrane protein location-dependent regulation by PI3K (III) and rabenosyn-5 in Drosophila wing cells. PLoS One. 2009;4:e7306.

21. Lemmon MA, Ferguson KM. Signal-dependent membrane targeting by pleckstrin homology (PH) domains. Biochem J. 2000;350(Pt 1):1-18.

22. Burks DJ, Wang J, Towery H, Ishibashi O, Lowe D, Riedel H, et al. IRS pleckstrin homology domains bind to acidic motifs in proteins. J Biol Chem. 1998;273:31061-7. 
23. Wang $Y$, Fei $D$, Vanderlaan $M$, Song A. Biological activity of bevacizumab, a humanized anti-VEGF antibody in vitro. Angiogenesis. 2004;7:335-45.

24. Lu KV, Bergers G. Mechanisms of evasive resistance to anti-VEGF therapy in glioblastoma. CNS Oncol. 2013;2:49-65.

25. Muller S, Kunkel P, Lamszus K, Ulbricht U, Lorente GA, Nelson AM, et al. A role for receptor tyrosine phosphatase $\zeta$ in glioma cell migration. Oncogene. 2003;22:6661-8.

26. Ulbricht U, Eckerich C, Fillbrandt R, Westphal M, Lamszus K. RNA interference targeting protein tyrosine phosphatase Z/receptor-type protein tyrosine phosphatase $\beta$ suppresses glioblastoma growth in vitro and in vivo. J Neurochem. 2006;98:1497-506.

27. Pantazaka E, Papadimitriou E. Chondroitin sulfate-cell membrane effectors as regulators of growth factor-mediated vascular and cancer cell migration. Biochim Biophys Acta. 1840;2014:2643-50.

28. Maeda N, Nishiwaki T, Shintani T, Hamanaka H, Noda M. 6B4 proteoglycan/ phosphacan, an extracellular variant of receptor-like protein-tyrosine phosphatase Z/RPTPß, binds pleiotrophin/heparin-binding growthassociated molecule (HB-GAM). J Biol Chem. 1996;271:21446-52.

29. Maeda N, Fukazawa N, Hata T. The binding of chondroitin sulfate to pleiotrophin/heparin-binding growth-associated molecule is regulated by chain length and oversulfated structures. J Biol Chem. 2006;281:4894-902.

30. Tanaka M, Maeda N, Noda M, Marunouchi T. A chondroitin sulfate proteoglycan PTP /RPTP $\beta$ regulates the morphogenesis of Purkinje cell dendrites in the developing cerebellum. J Neurosci. 2003;23:2804-14.

31. Bao X, Muramatsu T, Sugahara K. Demonstration of the pleiotrophin-binding oligosaccharide sequences isolated from chondroitin sulfate/dermatan sulfate hybrid chains of embryonic pig brains. J Biol Chem. 2005;280:35318-28.

32. Deepa SS, Umehara Y, Higashiyama S, Itoh N, Sugahara K. Specific molecular interactions of oversulfated chondroitin sulfate $\mathrm{E}$ with various heparinbinding growth factors. Implications as a physiological binding partner in the brain and other tissues. J Biol Chem. 2002;277:43707-16.

33. ten Dam GB, van de Westerlo EM, Purushothaman A, Stan RV, Bulten J, Sweep FC, et al. Antibody GD3G7 selected against embryonic glycosaminoglycans defines chondroitin sulfate-E domains highly up-regulated in ovarian cancer and involved in vascular endothelial growth factor binding. Am J Pathol. 2007;171:1324-33.

34. Park JE, Keller GA, Ferrara N. The vascular endothelial growth factor (VEGF) isoforms: differential deposition into the subepithelial extracellular matrix and bioactivity of extracellular matrix-bound VEGF. Mol Biol Cell. 1993;4:1317-26.

35. Parker MW, Xu P, Guo HF, Vander Kooi CW. Mechanism of selective VEGF-A binding by neuropilin-1 reveals a basis for specific ligand inhibition. PLoS One. 2012;7:e49177.

36. von Wronski MA, Raju N, Pillai R, Bogdan NJ, Marinelli ER, Nanjappan P, et al. Tuftsin binds neuropilin-1 through a sequence similar to that encoded by exon 8 of vascular endothelial growth factor. J Biol Chem. 2006;281:5702-10.

37. Lu KV, Jong KA, Kim GY, Singh J, Dia EQ, Yoshimoto K, et al. Differential induction of glioblastoma migration and growth by two forms of pleiotrophin. J Biol Chem. 2005;280:26953-64.

38. Bermek O, Diamantopoulou Z, Polykratis A, Dos Santos C, Hamma-Kourbali $Y$, Burlina F, et al. A basic peptide derived from the HARP C-terminus inhibits anchorage-independent growth of DU145 prostate cancer cells. Exp Cell Res. 2007:313:4041-50.

39. Heroult M, Bernard-Pierrot I, Delbe J, Hamma-Kourbali Y, Katsoris P, Barritault $D$, et al. Heparin affin regulatory peptide binds to vascular endothelial growth factor (VEGF) and inhibits VEGF-induced angiogenesis. Oncogene. 2004:23:1745-53.

40. Mikelis C, Lamprou M, Koutsioumpa M, Koutsioubas AG, Spyranti Z, Zompra $A A$, et al. A peptide corresponding to the C-terminal region of pleiotrophin inhibits angiogenesis in vivo and in vitro. J Cell Biochem. 2011;112:1532-43.

41. Shojaei F. Anti-angiogenesis therapy in cancer: current challenges and future perspectives. Cancer Lett. 2012;320:130-7.

\section{Submit your next manuscript to BioMed Central and take full advantage of:}

- Convenient online submission

- Thorough peer review

- No space constraints or color figure charges

- Immediate publication on acceptance

- Inclusion in PubMed, CAS, Scopus and Google Scholar

- Research which is freely available for redistribution

Submit your manuscript at www.biomedcentral.com/submit 